\title{
Variabilidade de isolados de Corynespora cassiicola (Berk. \& Curt.) Wei procedentes do Amazonas, em meios de cultura
}

\author{
Francy Mary Galúcio Sousa ${ }^{1}$, Jânia Lília da Silva Bentes ${ }^{1}$
}

\author{
${ }^{1}$ Laboratório de Microbiologia e Fitopatologia, Faculdade de Ciências Agrárias, Universidade Federal do Amazonas, Av. Rodrigo Otávio, CEP \\ 69077-000, Manaus, AM, Brasil \\ Autor para correspondência: Jânia Lília da Silva Bentes (jlbentes@ufam.edu.br) \\ Data de chegada: 19/08/2013. Aceito para publicação em: 03/02/2014.
}

1917

\section{RESUMO}

Sousa, F.M.G.; Bentes, J.L.S.. Variabilidade de isolados de Corynespora cassiicola (Berk. \& Curt.) Wei procedentes do Amazonas, em meios de cultura. Summa Phytopathologica, v.40, n.1, p.84-87, 2014.

Corynespora cassiicola, responsável por danos econômicos em dezenas de espécies de interesse comercial, na região Amazônica é o principal patógeno da parte aérea do tomateiro (Solanum lycopersicum L.). Neste trabalho, foram avaliadas as características morfológicas de C.cassiicola isolados de três hospedeiras no Amazonas. Foi estudada a variabilidade e a morfocultura de isolados de C. cassiicola nos meios de cultura Batata-Dextrose-Ágar (BDA), Batata-Sacarose-Ágar (BSA), Aveia-Ágar (AvA) e Cenoura-Ágar (CA). Discos de $5 \mathrm{~mm}$ de diâmetro retirados de colônias crescidas em meio BDA por 15 dias, foram transferidos para o centro de placas de Petri contendo os meios de cultura e mantidas à temperatura de laboratório $\left( \pm 26^{\circ} \mathrm{C}\right)$ sob luz contínua. Os tratamentos foram distribuídos sob esquema fatorial $15 \times 4$ (isolados x meios de cultura) com dez repetições. Maior índice de crescimento micelial ocorreu no meio CA e a maior esporulação nos meios BDA e BSA para os isolados de tomateiro e pepino. $\mathrm{O}$ aspecto das colônias variou quanto à coloração entre os isolados do mesmo hospedeiro e entre isolados de hospedeiros diferentes em todos os meios de cultura. O tamanho dos conídios variou de $41,40-81,20 \mu \mathrm{m}$ de comprimento por 4,30 - 6,95 $\mu \mathrm{m}$ de largura e apresentaram de 1 a 14 pseudosseptos.

Palavras-chave adicionais: mancha-de-corinéspora, crescimento micelial, esporulação. \begin{abstract}
Phytopathologica, v.40, n.1, p.84-87, 2014.
Corynespora cassiicola, responsible for economic losses in dozens of commercial species in the Amazon region, is the main pathogen affecting the shoot of tomato (Solanum lycopersicum L.). This study evaluated the morphological characteristics of C. cassiicola isolated from three hosts in Amazonas. The variability and the morpho-culture of $C$. cassiicola isolates were studied in the culture media Potato Dextrose Agar (PDA), Potato Sucrose Agar (PSA), Oatmeal Agar (VLE) and Carrot Agar (CA). Disks of $5 \mathrm{~mm}$ diameter, taken from colonies grown on PDA medium for 15 days, were transferred to
\end{abstract}

ABSTRACT

Sousa, F.M.G.; Bentes, J.L.S.. Variability of Corynespora cassiicola (Berk. \& Curt.) Wei isolates from Amazonas, in culture media. Summa

the center of Petri dishes containing the culture media and maintained at room temperature $\left( \pm 26^{\circ} \mathrm{C}\right)$ under continuous light. Treatments were arranged in a 4 $\mathrm{x} 15$ factorial (isolates $\mathrm{x}$ culture media) with ten replicates. The highest mycelial growth rate occurred in CA medium and the highest sporulation in the media PDA and PSA for isolates from tomato and cucumber. The aspect of colonies varied in color between isolates from the same host and between isolates from different hosts for all culture media. The size of conidia ranged from 41.40 to $81.20 \mu \mathrm{m}$ in length by 4.30 to $6.95 \mu \mathrm{m}$ in width and showed 1 to 14 pseudosepta.

Additional keywords: Corynespora spot, mycelial growth, sporulation.

O fungo Corynespora cassiicola (Berk. \& Curt.) Wei) causa doença em mais de 70 espécies de plantas em países de clima tropical e subtropical (15). É um patógeno cosmopolita, inespecífico e altamente severo na Região Norte do país, principalmente em culturas das famílias Solanaceae e Cucurbitaceae (13). No Amazonas, até o ano de 2001, ainda não havia relatos do patógeno causando doença em pepino no Estado (2). Porém, em 2009, Reis e Madeira (13), constataram nos municípios de Manaus, Iranduba e Silves, alta severidade em folhas de pepinos e tomateiros estabelecidos em cultivos protegidos e em convencionais.

No País, há poucos relatos sobre a caracterização morfológica de isolados de $C$. cassiicola $(1,4,8,16)$ e nenhum de isolados do Estado do Amazonas, onde o patógeno é importante em várias culturas (13).

Por meio da caracterização morfológica das colônias, micélio e conídios é possível determinar as variações entre os isolados de diferentes hospedeiros, além de obter importantes informações para estudos relacionados com a físiologia do patógeno e composição química de meios de cultura que favoreçam o crescimento micelial e a esporulação (3), e o desenvolvimento de métodos de controle químico, genético ou cultural, os quais podem propiciar o manejo adequado da doença (16).

Este trabalho objetivou caracterizar a variabilidade de C. cassiicola quanto ao crescimento micelial, produção de conídios e aspecto da colônia em diferentes meios de cultura. 
Foram utilizados 15 isolados de C. cassiicola coletados em diferentes municípios do estado do Amazonas (Tabela 1). O isolamento indireto do fungo foi feito a partir de fragmentos retirados de folhas apresentando sintomas típicos da doença. Foram obtidas culturas monospóricas para todos os isolados e mantidas em tubos de ensaio contendo o meio de cultura BDA inclinado, em incubadora BOD a $27^{\circ} \mathrm{C}$.

A caracterização dos isolados foi feita cultivando nos meios de cultura BDA (Batata-Dextrose-Ágar: batata $200 \mathrm{~g}$; dextrose $20 \mathrm{~g}$; ágar 17 g e água destilada $1000 \mathrm{~mL}$ ); BSA (Batata-Sacarose-Ágar: batata $200 \mathrm{~g}$; sacarose $20 \mathrm{~g}$; ágar $17 \mathrm{~g}$ e água destilada, $1000 \mathrm{~mL}$ ); AvA (Aveia-Ágar: aveia 75 g; ágar $17 \mathrm{~g}$ e água destilada, $1000 \mathrm{~mL}$ ) e CA (Cenoura- Ágar: cenoura 20 g; ágar $17 \mathrm{~g}$ e água destilada, $1000 \mathrm{~mL}$ ).

Para a avaliação do crescimento micelial, disco de $5 \mathrm{~mm}$ de diâmetro de meio com o mícélio do fungo foi transferido para o centro de placas de Petri com nove centímetros de diâmetro contendo os meios de cultura relatados anteriormente. As placas foram mantidas em temperatura de laboratório $\left( \pm 26^{\circ} \mathrm{C}\right)$. O delineamento experimental foi inteiramente ao acaso, em esquema fatorial $15 \times 4$ (isolados $\mathrm{x}$ meios de cultura) com dez repetições, cada unidade experimental constituída por uma placa de Petri.

As avaliações do crescimento micelial foram realizadas em dias alternados, iniciadas no terceiro dia de cultivo, com o auxílio de uma régua graduada, registrando as medidas das colônias, em sentidos diametralmente opostos, até que um dos tratamentos atingisse a borda da placa. Foi calculado o índice de crescimento micelial (ICM) dos isolados conforme a fórmula descrita por Peres et al. (12). Os valores de ICM foram analisados estatisticamente e as médias comparadas pelo teste de Tukey a 5\%, usando programa SAEG 9.0.

Aos 30 dias, foi avaliada a produção de conídios pelo método de contagem em gota, nas mesmas placas usadas para avaliar o crescimento micelial. Foi preparada uma suspensão de esporos adicionando $20 \mathrm{~mL}$ de água destilada esterilizada nas placas e com o auxílio de um pincel de cerdas macias, os conídios foram removidos dos conidióforos. A suspensão foi recolhida em um béquer e adicionados $10 \mu \mathrm{L}$ de solução de Tween 80. Em uma lâmina para microscopia foram depositadas separadamente três gotas de $10 \mu \mathrm{L}$ da suspensão, e quantificado o número de conídios em cada gota, em microscópio Olympus sob objetiva de 40x. Em seguida, foi calculado o número de conídios $\mathrm{mL}^{-1}$. Os dados obtidos foram transformados utilizando a fórmula $\sqrt{(\mathrm{x}+0,5)}$ e submetidos à análise de variância e, quando detectadas diferenças significativas, as médias foram comparadas pelo Teste de Tukey a $5 \%$ de probabilidade. Além do crescimento micelial e produção de conídios, foram avaliadas a coloração da colônia, o aspecto do micélio e o tamanho dos conídios. A coloração das culturas foi descrita conforme o sistema de Munsell Color Company (9) de anotação de cores e as descrições dos aspectos morfológicos foram efetuadas nas colônias com 25 dias de cultivo.

O comprimento, a largura e o número de septos foram quantificados em 50 conídios para cada tratamento, com auxílio de uma ocular micrométrica. Os dados foram submetidos à análise de variância, e quando detectadas diferenças significativas, as médias foram comparadas pelo Teste de Tukey a 5\% de probabilidade.

Maior crescimento micelial ocorreu no meio CA para todos os isolados testados (Tabela 1). Alguns autores observaram maior crescimento micelial de $C$. cassiicola nos meios V-8, alimento infantil, extrato de soja (1), BDA e BDA 500 (14).

A maior produção de conídios ocorreu nos meios BDA e BSA para os isolados de tomateiro (Tabela 1). Em outros estudos houve maior produção de conídios nos meios $\operatorname{BDA}(10,15), \mathrm{V}-8$, alimento infantil (1) e Czapeck-ágar (14).

Segundo Griffin (7), os meios de cultura podem determinar

Tabela 1. Médias do índice de crescimento micelial e produção de conídio de Corynespora cassiicola em diferentes meios de cultura.

\begin{tabular}{|c|c|c|c|c|c|c|c|c|c|c|}
\hline \multirow{2}{*}{ Isolados } & \multirow{2}{*}{ Hospedeiro } & \multirow{2}{*}{ Procedência } & \multicolumn{4}{|c|}{ Índice de Crescimento micelial $^{\text {k*k }}$} & \multicolumn{4}{|c|}{$\mathbf{N}^{\circ}$ Conídios. $\mathbf{m L}^{-\mathbf{1}^{* *}}$} \\
\hline & & & BDA $^{*}$ & BSA & AvA & $\mathbf{C A}$ & BDA & BSA & AvA & CA \\
\hline 1 & Tomateiro & Iranduba-AM & $3,62 \mathrm{a}$ & 3,48 a & $3,48 \mathrm{a}$ & $2,74 \mathrm{~b}$ & $328,13 \mathrm{a}$ & $354,60 \mathrm{a}$ & $109,03 \mathrm{~b}$ & $211,30 \mathrm{~b}$ \\
\hline 2 & Tomateiro & Iranduba-AM & $3,52 \mathrm{a} \mathrm{b}$ & $3,22 \mathrm{~b}$ & $3,94 \mathrm{a}$ & $2,64 \mathrm{c}$ & $406,20 \mathrm{a}$ & $399,60 \mathrm{a}$ & $54,17 \mathrm{c}$ & $214,70 \mathrm{~b}$ \\
\hline 3 & Tomateiro & Presidente Figueiredo-AM & $3,64 \mathrm{~b}$ & $3,54 \mathrm{~b}$ & $2,86 \mathrm{c}$ & $4,10 \mathrm{a}$ & $335,07 \mathrm{a}$ & $266,43 \mathrm{a}$ & $97,83 \mathrm{~b}$ & $234,10 \mathrm{a}$ \\
\hline 4 & Tomateiro & Manaus-AM & $3,26 \mathrm{~b}$ & $2,82 \mathrm{c}$ & $2,88 \mathrm{~b} \mathrm{c}$ & 3,98 a & $347,10 \mathrm{a}$ & $219,43 \mathrm{~b} \mathrm{c}$ & $140,93 \mathrm{c}$ & $286,30 \mathrm{a} \mathrm{b}$ \\
\hline 5 & Tomateiro & Manaus-AM & $4,14 \mathrm{a}$ & $4,12 \mathrm{a}$ & $3,30 \mathrm{~b}$ & $4,42 \mathrm{a}$ & $235,23 \mathrm{a}$ & $180,43 \mathrm{a} \mathrm{b}$ & $106,77 \mathrm{~b} \mathrm{c}$ & $60,63 \mathrm{c}$ \\
\hline 6 & Pepino & Manaus-AM & $4,28 \mathrm{~b}$ & $4,34 \mathrm{a} \mathrm{b}$ & $3,92 \mathrm{~b}$ & $4,76 \mathrm{a}$ & $194,43 \mathrm{~b}$ & $329,70 \mathrm{a}$ & $32,47 \mathrm{c}$ & $117,53 \mathrm{~b} \mathrm{c}$ \\
\hline 7 & Pepino & Iranduba-AM & $4,22 \mathrm{a} \mathrm{b}$ & $3,96 \mathrm{ab}$ & $3,90 \mathrm{~b}$ & $4,38 \mathrm{a}$ & $15,50 \mathrm{a}$ & $14,57 \mathrm{a}$ & 7,43 a & $7,00 \mathrm{a}$ \\
\hline 8 & Pepino & Iranduba-AM & $4,12 \mathrm{a} \mathrm{b}$ & $4,24 \mathrm{a} \mathrm{b}$ & $3,82 \mathrm{~b}$ & $4,54 \mathrm{a}$ & $14,50 \mathrm{a}$ & $55,17 \mathrm{a}$ & $8,53 \mathrm{a}$ & $11,40 \mathrm{a}$ \\
\hline 9 & Pepino & Manaus-AM & $3,90 \mathrm{a} \mathrm{b}$ & $3,78 \mathrm{~b}$ & $3,96 \mathrm{a} \mathrm{b}$ & $4,24 \mathrm{a}$ & $46,60 \mathrm{a}$ & $85,97 \mathrm{a}$ & $18,43 \mathrm{a}$ & $6,60 \mathrm{a}$ \\
\hline 10 & Pepino & Presidente Figueiredo-AM & $4,08 \mathrm{a}$ & 3,96 a & $4,04 \mathrm{a}$ & $4,34 \mathrm{a}$ & $74,23 \mathrm{a}$ & $8,93 \mathrm{a}$ & $13,83 \mathrm{a}$ & $8,17 \mathrm{a}$ \\
\hline 11 & Berinjela & Presidente Figueiredo-AM & $3,98 \mathrm{a} \mathrm{b}$ & $4,28 \mathrm{a}$ & $3,58 \mathrm{~b}$ & $4,30 \mathrm{a}$ & $233,57 \mathrm{a}$ & $287,23 \mathrm{a}$ & $68,43 \mathrm{~b}$ & $222,67 \mathrm{a}$ \\
\hline 12 & Berinjela & Presidente Figueiredo-AM & $3,44 \mathrm{a}$ & $3,72 \mathrm{a}$ & $3,56 \mathrm{a}$ & $3,70 \mathrm{a}$ & $252,80 \mathrm{a} \mathrm{b}$ & $287,60 \mathrm{a}$ & $218,87 \mathrm{a} b$ & $178,47 \mathrm{~b}$ \\
\hline 13 & Berinjela & Presidente Figueiredo-AM & $2,60 \mathrm{~b}$ & $2,42 \mathrm{~b}$ & $2,34 \mathrm{~b}$ & $3,30 \mathrm{a}$ & $34,13 \mathrm{ab}$ & $125,20 \mathrm{a}$ & $7,43 \mathrm{~b}$ & $8,63 \mathrm{~b}$ \\
\hline 14 & Berinjela & Presidente Figueiredo-AM & $2,58 \mathrm{~b}$ & $2,88 \mathrm{~b}$ & $2,92 \mathrm{~b}$ & $4,12 \mathrm{a}$ & $292,07 \mathrm{~b}$ & $405,60 \mathrm{a}$ & $63,13 \mathrm{c}$ & $95,40 \mathrm{c}$ \\
\hline 15 & Berinjela & Presidente Figueiredo-AM & $2,80 \mathrm{~b}$ & $2,78 \mathrm{~b}$ & $2,96 \mathrm{~b}$ & $3,46 \mathrm{a}$ & $11,63 \mathrm{a}$ & $16,80 \mathrm{a}$ & $8,07 \mathrm{a}$ & $6,60 \mathrm{a}$ \\
\hline
\end{tabular}

"BDA = Batata-Dextrose-Ágar; BSA = Batata-Sacarose-Ágar; AVA = Aveia-Ágar; CA = Cenoura-Ágar.

*** Médias seguidas pela mesma letra minúscula na linha não diferem entre si pelo teste de Tukey a $5 \%$ de probabilidade. 
comportamentos distintos entre isolados, visto que cada isolado pode metabolizar os nutrientes em velocidades diferentes, ocasionando a síntese de outras moléculas ou produtos que podem influenciar o crescimento do fungo.

Segundo Dhingra e Sinclair (3) e Pereira et al. (11), o meio de cultura pode afetar o crescimento e/ou a esporulação, pois pode favorecer a esporulação não necessariamente o crescimento micelial, podendo explicar o fato de C. cassiicola apresentar maior ou menor índice de crescimento micelial nos meios de cultura testados.

$\mathrm{O}$ aspecto e a coloração das colônias variaram entre os isolados do mesmo hospedeiro e entre isolados de hospedeiros diferentes em todos os meios de cultura. Nos meios BDA e BSA, a coloração das colônias variou de cinza a cinza escuro, no AvA, predominantemente, foi cinza claro e, no CA, a maioria dos isolados apresentou coloração hialina a cinza claro. Quanto ao aspecto das colônias, todos os isolados apresentaram micélio aéreo cotonoso nos meios BDA, BSA e AvA, enquanto que no meio CA a maioria dos isolados apresentou aspecto aéreo (Figura 1). Peres et al. (12) observaram variação na coloração e tipo de micélio de Colletotrichum gloeosporioides (Penz.) Penz. Sacc. de acordo com o meio de cultura utilizado, demonstrando a existência de variabilidade entre isolados crescidos em um mesmo meio e entre os diferentes meios, o que pode estar relacionado a fonte de nutriente a que têm acesso e ao aproveitamento dos nutrientes contidos nos meios de cultura. O mesmo pode ter ocorrido com os isolados de C. cassiicola avaliados neste estudo.

As dimensões dos conídios de C. cassiicola variaram de 41,40 $81,20 \mu \mathrm{m}$ de comprimento por 4,30 - 6,95 $\mu \mathrm{m}$ de largura e o número de pseudosseptos de um a catorze. Ellis (5) descreveu os conídios de C. cassiicola variando de 40,0 - 220,0 $\mu \mathrm{m} \times 9,0$ - 22,0 $\mu \mathrm{m}$ e número de pseudosseptos variando de quatro a vinte, o que permite classificar o fungo como C. cassiicola.

Segundo Gasparotto e Pereira (6), os conidióforos e conídios de C. cassiicola podem variar morfologicamente de acordo com a umidade do ambiente em que são produzidos. No hospedeiro, em condições não excessivas, os conídios são produzidos de forma simples e apicalmente no conidióforo, são marrom-claros a hialinos, têm de 5 a 20 pseudosseptos e medem de 40 - $220 \mu \mathrm{m}$ x 6 - $20 \mu \mathrm{m}$. Em condições naturais com umidade elevada, os conidióforos e

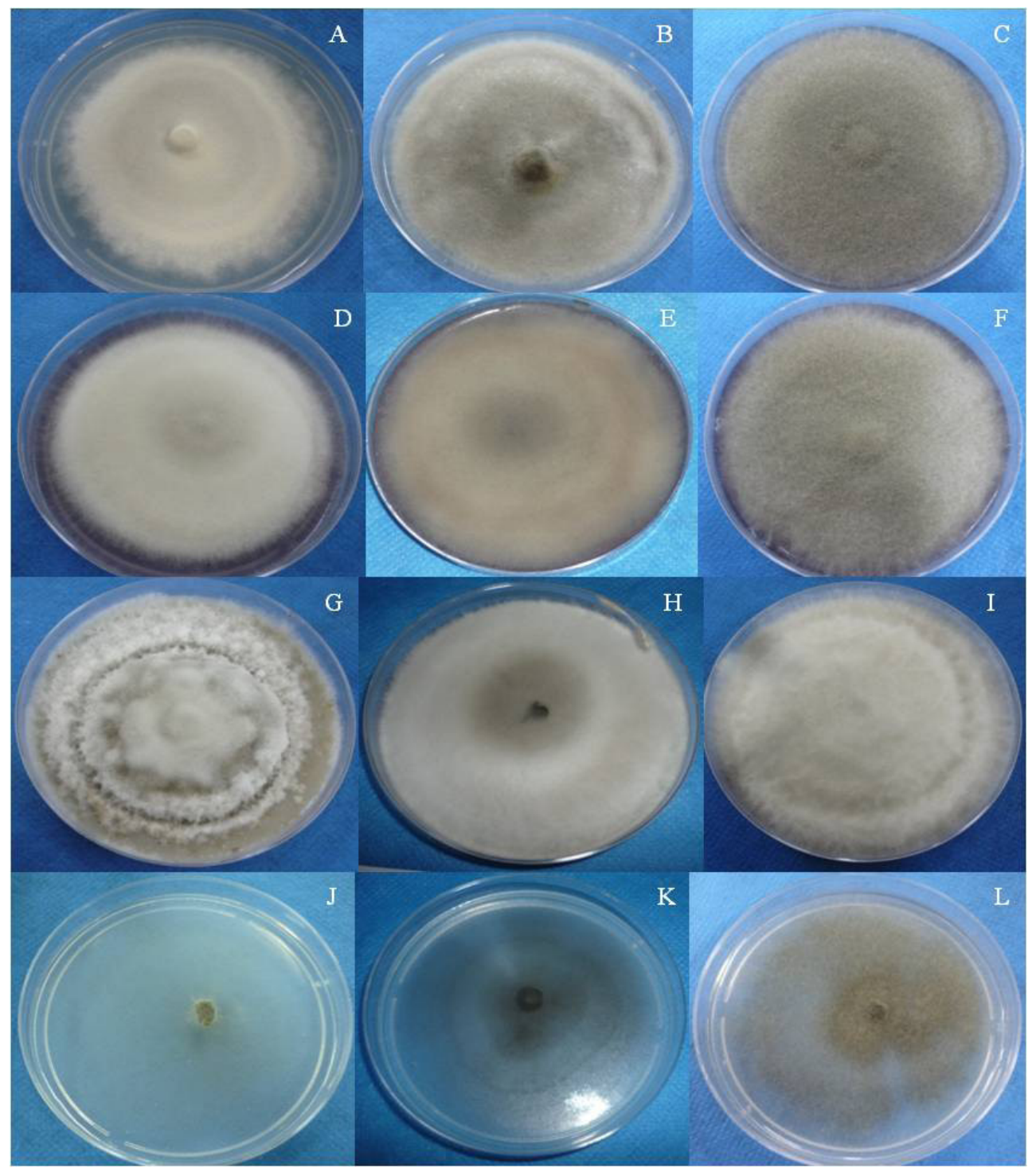

Figura 1. Variabilidade morfocultural de isolados de Corynespora cassiicola. Em (A), (B), (C), isolados de tomateiro, pepino e berinjela em meio BDA; (D), (E), $(\mathrm{F})$, isolados de tomateiro, pepino e berinjela em meio BSA; $(\mathrm{G}),(\mathrm{H}),(\mathrm{I})$, isolados de tomateiro, pepino e berinjela em meio AVA; (J), (K), (L), isolados de tomateiro, pepino e berinjela em meio CA. 
conídios são geralmente longos e afiados, o que dificulta a distinção dos pseudosseptos dos esporos. Em meio de cultura, a produção das estruturas reprodutivas é distinta das produzidas em condições naturais, sendo os conidióforos pouco distintos das hifas que os produzem e a produção de conídios ocorre frequentemente em cadeia, com bastante variação morfológica individual.

Houve variabilidade nas características morfológicas entre isolados do mesmo hospedeiro e de diferentes procedências nos meios de cultura testados, sendo o meio CA o que favoreceu o maior índice de crescimento micelial e, BDA e BSA, os que favoreceram maior esporulação.

\section{REFERÊNCIAS BIBLIOGRÁFICAS}

1. Almeida, A. M. R.; Yamashita, J. Crescimento e esporulação de Corynespora cassiicola (Berk. \& Curt.) Wei em diferentes meios de cultura. Fitopatologia Brasileira, Brasília, DF, v.1, n.3, p.203-206, 1976.

2. Cardoso, M. O.; Boher, B.; Ávila, A. C.; Assis, L. A. G. Doenças das cucurbitáceas no Estado do Amazonas. Circular Técnica, Embrapa Amazônia Ocidental, Manaus, n. 9, p. 1-14, 2001.

3. Dhingra, O. D.; Sinclair, J. B. Basic plant pathology methods. Boca Raton: Lewis, 1995.

4. Duarte, M. L. R.; Albuquerque, F. C.; Prabhu, A. S. Uma nova enfermidade foliar do cacaueiro (Theobroma cacao L.) causada pelo fungo Corynespora cassiicola (Berk. \& Curt.) Wei. Fitopatologia Brasileira, Brasília, DF, v. 3, n. 3, p. 259-265, 1983.

5. Ellis, M.B. Dematiaceous Hyphomycetes. Kew: Surrey, Commonwealth Mycological Institute, 1971. 608 p.
6. Gasparotto, L.; Pereira, J. C. R. Doenças da seringueira no Brasil. Brasília: EMBRAPA, 2012, 2 ed., 255 .

7. Griffin, D.H. Fungal physiology. New York: John Wiley, 1993. 458 p.

8. Melo, M.M. Produção de esporos e inoculação de Corynespora cassiicola em soja. 2009. 76 p. Dissertação (Mestrado em Agronomia) - Universidade de Passo Fundo, Rio Grande do Sul.

9. Munsell Color Company. Munsell soil color charts. Baltimore, 1975.

10. Olive, L. S.; Bain, D.C.; Lefebvre, C. L. A leaf spot of cowpea and soybean caused by an undescribed species of Helminthosporium. Phytopatology, St. Paul, v. 35, p. $822-831,1945$.

11. Pereira, L.; Silva, G. S.; Ribeiro, V. Q. Caracterização fisiológica, cultural e patogênica de diferentes isolados de Lasiodiplodia theobromae. Fitopatologia Brasileira, Brasília, DF, v.31, p.572-578, 2006.

12. Peres, A.P.; Silva-Mann, R.; Vieira, M. G. G. C.; Machado, J. C. Variabilidade morfocultural e genética de fungos associados à podridão peduncular do mamão. Ciências Agrotécnicas, Lavras, v.27, n.5, p.1053-1062, 2003.

13. Reis, A.; Madeira, N. R. Diagnóstico dos principais problemas no cultivo de hortaliças no Estado do Amazonas. Circular Técnica, Embrapa Hortaliças, Brasília, DF, n. 82, 2009, 12 p.

14. Roim, F. F. B. Morfologia e patologia de isolados de Corynespora cassiicola obtidos de mancha foliar (mancha-alvo) e podridão radicular da soja. 2001. 77 f. Dissertação (Mestrado em Agronomia) - Universidade Estadual Paulista Júlio de Mesquita Filho, Jaboticabal.

15. Silva, W. P. K.; Multani, D. S.; Deverall, B. J.; Lyon, B. R. RFLP and RAPD analyses in the identification and differentiation of isolates of the leaf spot fungus. Australian Journal of Botany, Collingwood, v. 43, n. 6, p. 609-618, 1995.

16. Teramoto, A. Caracterização morfológica, fisiológica, isoenzimática e controle de isolados de Corynespora cassiicola (Berky \& Curt) Wei, agente causal da mancha alvo. 2008. 81 p. Tese (Doutorado em Produção Vegetal) - Universidade Federal de Goiás, Goiânia. 